\title{
Elena Castro Martínez: una científica apasionada con la innovación
}

\section{Por Rosa Isusi-Fagoaga ${ }^{1}$}

Entrevista realizada en la Ciudad Politécnica de la Innovación, Valencia [España], el 17de noviembre de 2017

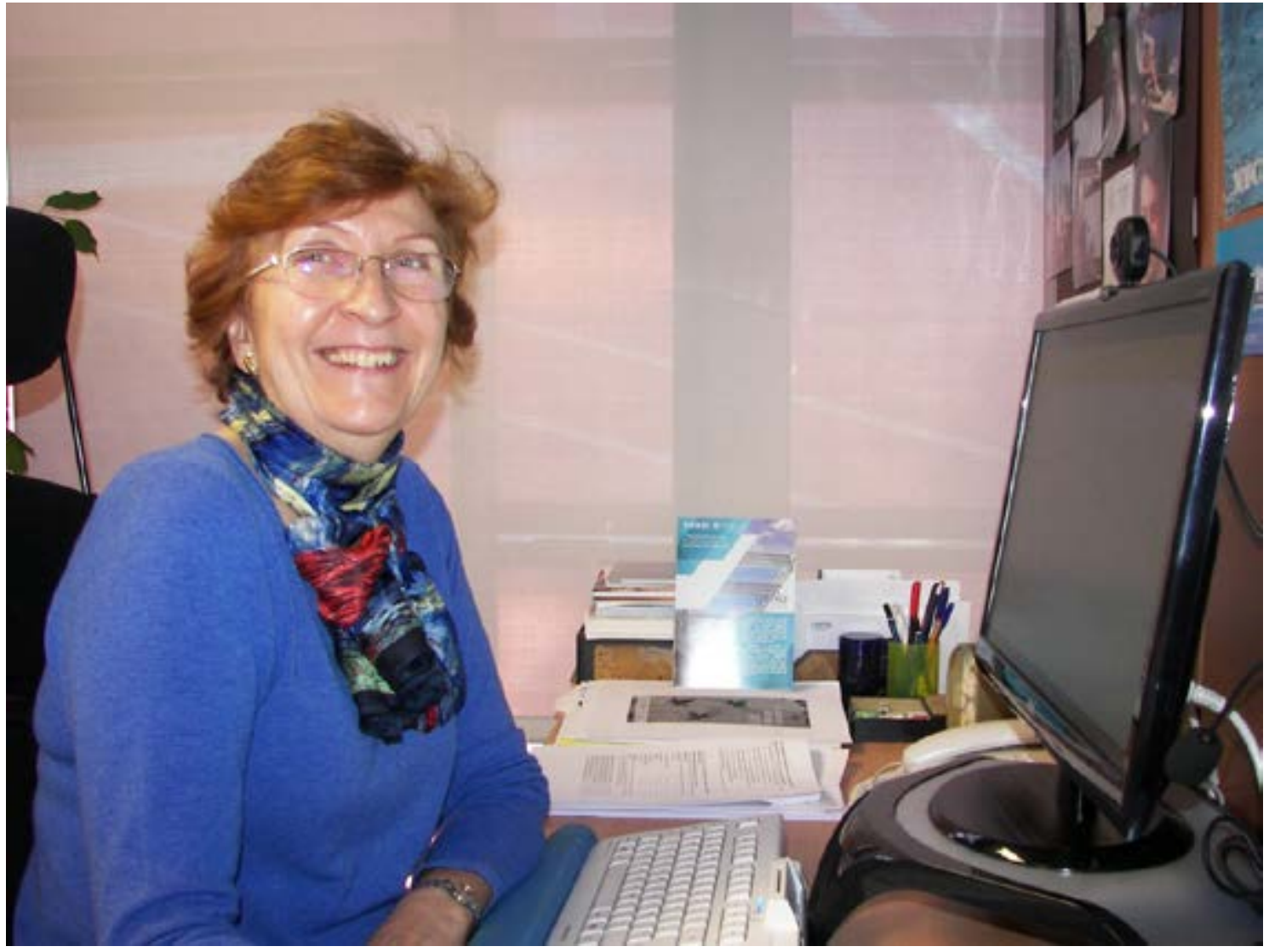

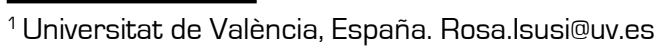




\section{Curriculum vitae}

Elena Castro Martínez es Científica titular de INGENIO (Instituto de gestión de la innovación y del conocimiento] y del CSIC-UPV [Consejo Superior de Investigaciones científicas - Universitat Politècnica de València].

\section{http://www.ingenio.upv.es/es/Elena-Castro-Martinez}

Es licenciada en Ciencias Químicas por la Universidad Complutense de Madrid en 1978 y doctora en Química Industrial por la misma Universidad en 1983. Participa en proyectos de investigación [nacionales e internacionales] sobre las políticas públicas de investigación científica e innovación y, en particular, sobre las relaciones entre investigadores y agentes sociales en materia de innovación; en 2004 inició una línea de investigación pionera sobre el intercambio y la y sobrela innovación social y cultural. Es autora de más de 50 publicaciones [artículos en revistas internacionales, libros y capítulos de libro] y de más de 20 informes técnicos, consecuencia de los contratos de I+D y consultoría en los que ha participado. También asesora a diversas entidades públicas [gobiernos regionales, entidades de investigación] y privadas sobre gestión de la ciencia y de la innovación y diseño y evaluación de políticas científicas y de innovación, tanto españolas como de América Latina.

La primera etapa de su carrera [1979-2004] se orientó a la gestión de la investigación y la transferencia de conocimiento en diversas entidades españolas [Centro para el Desarrollo Tecnológico Industrial-CDTI, Ministerio de Educación y Ciencia, Consejo Superior de Investigaciones Científicas CSIC], desarrollando actividades relacionadas con la planificación y la gestión de la ciencia y la tecnología.

Habitualmente imparte clases, conferencias y dirige cursos y seminarios sobre su especialidad, tanto en España como en países latinoamericanos en cooperación con entidades diversas, entre las que destaca la Agencia Española de Cooperación internacional para el Desarrollo y la Organización de Estados Iberoamericanos, así como las Universidades de Oviedo, Santiago de Compostela y Salamanca.

Desde 2002, forma parte del grupo de indicadores de la Red de OTRI de las Universidades españolas. Es miembro de la Eu-SPRI Forum y de la Red Transversal de Estudios de Género en Ciencias Humanas, Sociales y Jurídicas [GENET]. Es miembro de la Asociación de Mujeres Investigadoras y tecnólogas (http://www.amit-es.org]. Desde 2013 es miembro del Consejo asesor de la Red Iberoamericana de Indicadores de Ciencia y Tecnología [RICYT].

\section{En su libro El significado de innovar (2013) en coautoría con Ignacio Fernández de Lucio hace un repaso por el concepto de innovación y su trasformación desde una connotación}




\section{negativa en sus orígenes hacia una positiva desde el s. XIX hasta nuestros días, mostrando gran cantidad de ejemplos. ¿Cómo surgió el libro? ¿Responde a una voluntad personal o a una necesidad institucional?}

En primer lugar, tengo claro que la misión de un científico es multidimensional, tiene que producir conocimientos, pero no basta con eso, es necesario transcender y poner el conocimiento en manos de los demás científicos mediante publicaciones y congresos. También es misión nuestra formar a otras personas; no soy docente, soy investigadora, pero tengo también una vertiente docente en diversos másteres. Considero que la investigación debe ir incorporándose a la docencia, mucho más en la fase de formación de doctores. Es como una carrera de relevos. Me viene a la mente un ejemplo bien significativo en la escultura de la rotonda de la avenida Blasco Ibáñez con avenida de Aragón, en la que un hombre caído [como metáfora del científico que acaba su carrera] cede su antorcha al que va a caballo y que seguirá su camino.

En segundo lugar, es creciente el efecto social de los investigadores. En el caso de las Humanidades, siempre ha formado parte de su quehacer la divulgación a la sociedad, porque son conscientes de que deben contribuir a la cultura de los ciudadanos, pero la ciencia nos afecta cada día más [piénsese en temas como las células madre, la nanotecnología, la inteligencia artificial,...) y, por eso, debe formar parte de nuestra cultura como ciudadanos. Los científicos pueden contribuir a formar un criterio en la ciudadanía, para que no sea manipulada. En este sentido, desde los gobiernos se están desarrollando políticas de fomento de la cultura científica y las universidades y el CSIC lo han incorporado a su misión llevando a cabo diferentes iniciativas, como puede ser la semana de la ciencia. En el caso del CSIC, hace años que publica una colección que lleva por título ¿Qué sabemos de...? Por ejemplo, los alimentos que tenemos, la inteligencia artificial...Es una grandísima colección que se hace en colaboración con la Editorial Los Libros de la catarata y que está teniendo una estupenda difusión. Cuando vi la colección pensé que desde el INGENIO no debíamos dejar pasar la oportunidad de dar visibilidad a lo que hacemos y explicarlo a la sociedad. Conseguí convencer a Ignacio y escribimos el libro. Fue muy difícil porque tuvimos que intentar que fuera riguroso, se entendiera bien y que a la vez fuera entretenido. Tengo una fuerte convicción personal de que debemos llegar a la sociedad. Nunca antes había escrito un material dirigido a divulgar el conocimiento científico pero estamos muy satisfechos de haberlo hecho.

\section{¿Qué opina sobre la utilización del concepto de innovación en nuestros días? ¿Se utiliza correctamente? ¿Está sobrevalorado? ¿Vivimos obsesionados con innovar?}

La obsesión ha sido más a finales del siglo pasado. Van cambiando las modas. El boom de la innovación tuvo lugar durante los años 80 del siglo pasado. Schumpeter había escrito en 1934 su libro sobre la innovación y su impacto en la economía, pero sus ideas no se difundieron masivamente hasta la década de 1970 sobre todo promovidas por la economía estadounidense. 
Desde entonces, las empresas empiezan a hacer un esfuerzo enorme en investigación e innovación, y se pudo comprobar que los sectores basados en nuevos conocimientos y tecnologías eran los que más crecian. Eso hizo que la OCDE, la organización internacional que ayuda a los gobiernos a diseñar políticas, se interesara por la innovación. Se necesitaban herramientas para hacer crecer a las economías y que fueran mejor. Primero la innovación se veía con más claridad en las empresas de alta tecnología, pero luego se pudo comprobar que, en realidad, la mayoría de las empresas que van bien son innovadoras y ahora se ha extendido el interés por analizar otros contextos en los que la innovación ha podido ser factor de éxito, como la propia administración o el tercer sector. Nosotros, por ejemplo, estudiamos la innovación en el sector cultural.

Cuando hablamos de innovación intentamos hacer las cosas mejor, más eficientemente y debemos conseguir que eso sea el devenir habitual. El problema es que toda innovación lleva aparejado un componente de riesgo, todas las empresas, negocios o proyectos innovadores deben asumir ese riesgo, esa incertidumbre de si funcionará o no.

\section{¿Cuál sería el papel de las universidades respecto a la innovación?}

Las universidades tienen muchísimo que decir y gestionar respecto a la innovación. Las universidades generan y tienen gran cantidad de conocimientos, pueden asesorar [utilizar el conocimiento acumulado que les hace falta a las empresas y otros agentes sociales], colaborar con otras entidades, organizar proyectos de investigación conjuntos, publicaciones, difusión a profesionales y divulgación social.

Pero no se olvide que la primera misión de las universidades es la docencia, enseñar contenidos y formar a personas cualificadas en un área específica. Es decir, que las universidades en primer lugar deben proporcionar a la sociedad profesionales cualificados para involucrarse en procesos innovadores. Las personas innovadoras tienen unas capacidades fuera de lo común, son muy creativas, con una buena dosis de entusiasmo, que trabajan en equipo y esos aspectos deberían formar parte de la formación si las universidades quieren desempeñar un papel activo en estos procesos. La segunda misión de las universidades es fomentar la investigación para mejorar el sistema y la sociedad. Y además, la tercera misión sería la transferencia del conocimiento, es decir, esforzarse para que los resultados de las investigaciones realizadas lleguen a la sociedad para que esta puede utilizar los conocimientos nuevos cuanto antes o bien colaborar con la sociedad para generar conjuntamente el nuevo conocimiento que se precisa. Por ejemplo, si nos centramos en el caso que hemos estudiado de la música en nuestro proyecto de innovación cultural. El musicólogo puede publicar sus transcripciones de obras musicales en un libro pero no sabemos si alguien que pueda utilizarlas lo va a leer. Sería necesaria una comunicación con posibles intérpretes para que tocaran esa música y llegara así a la sociedad. No solo hay que investigar sino pensar cuáles son los cauces para transferir ese conocimiento. Preparar un encuentro o 
seminario con interesados en ese repertorio publicado, intérpretes o directores de festivales donde se pueda interpretar y decir aquí tenéis el libro de las partituras para poder tocarlas y para que puedan aplicar el conocimiento generado por la investigación. Si los intérpretes no van a los archivos, el material de los archivos tendrá que llegar a ellos de forma accesible.

\section{¿Existe alguna diferencia entre transferencia del conocimiento y divulgación del conocimiento científico o académico?}

Hay varios términos que utilizamos en el mismo contexto. La transferencia del conocimiento es el paso del investigador hacia aquél que lo va a aplicar. Transferencia es cuando hay implicación del investigador en el proceso de aplicación. Al transferir me tengo que esforzar para que el que lo tenga que usar lo pueda hacer.

Difusión sería un término amplio, en el que no existe una implicación directa del científico. Puedes escribir un libro y ahí queda. La difusión puede ser entre profesionales o difusión social. Esta última sería como divulgación.

La divulgación sería la comunicación al público a la sociedad, donde hay impacto social. En este caso tengo que adaptar el mensaje al público y son muy importantes las formas y los medios.

Por ejemplo, cuando el grupo La Grande Chapelle, dirigido por Albert Recasens, quiso grabar un disco con música para Don Quijote,su director se puso en contacto con Lola Josa, profesora de Literatura de la Universitat de Barcelona y con Mariano Lambea, musicólogo del CSIC. Lola, que conocía muy bien la novela, les indicó qué textos podían utilizar y entre Mariano y Albert, ambos expertos en música barroca, seleccionaron las músicas. La colaboración entre ellos generó un nuevo conocimiento, una nueva creación, una primera grabación mundial, una innovación. No se trataba de que Lola Josa dijera a los intérpretes aquí tenéis el libro de Don Quijote y los intérpretes, aquí está la música del s. XVII. Tenían que colaborar, trabajar juntos, intercambiar conocimientos hasta generar algo nuevo, innovador. Fue una transferencia de conocimiento en doble sentido. Casi siempre los investigadores en interacción con las personas que aplican el conocimiento que ellos han generado incorporan nuevas formas de investigar, como mínimo, incorporan las necesidades de los usuarios específicos en muchos casos también otras cuestiones importantes.

\section{¿Cómo se podría innovar en el ámbito de las Ciencias Sociales y concretamente en Educación? ¿Tiene alguna sugerencia?}

En el sistema educativo español es muy difícil ser innovador porque está muy reglado y es casi imposible innovar en contenidos, la única innovación que parece ser aceptada es la forma de trabajar. Por ejemplo, se podría innovar en los objetivos, para trabajar actitudes, en la manera de relacionarse con alumnado, trabajando más en equipo, utilizando metodologías más activas, 
elaborando materiales nuevos, aprovechando nuevos espacios y sobre todo innovar en los enfoques. Hace poco escribí un artículo con Mariano Martín-Gordillo, profesor de Educación Secundaria, en el que se proponía una innovación en la forma de evaluar, porque, aunque muchas veces se trabaja en equipo, luego se sigue evaluando individualmente a los alumnos.

\section{¿Cuál es la función que realiza una investigadora del CSIC con una trayectoria tan interesante como usted? ¿Podría contarnos algo de su día a día en el INGENIO de la UPV?}

Nuestra misión es investigar, comunicar nuestros resultados a los colegas, formar nuevos investigadores y especialistas, transferir nuestro conocimiento a los agentes sociales y divulgar nuestro conocimiento a la sociedad, jahí es nada! No tenemos una rutina fija, hacemos muchas cosas diferentes en las distintas épocas del año, en función, muchas veces, de estímulos externos. Por ejemplo, cuando se publican convocatorias para proyectos de I+D, dedicamos mucho tiempo a la preparación de las propuestas, sobre todo, si son internacionales. También nos implicamos en la organización de congresos, investigaciones con otros colegas e instituciones, asistimos a congresos nacionales e internacionales, acogemos y formamos a otros investigadores, tenemos docencia en másteres, elaboramos informes para otras instituciones y otras muchas cosas que van surgiendo en torno al mundo de la innovación. ¡Somos multidimensionales y polifacéticos! 